\section{What is already known on this topic}

Unconventional testing for allergy, such as electrodermal testing, is widely available

Few clinical trials have evaluated unconventional testing

\section{What this study adds}

Electrodermal testing cannot distinguish between atopic and non-atopic individuals as previously determined by skin prick tests

trials. We conclude that electrodermal testing cannot diagnose allergy to common aeroallergens such as cat dander and house dust mite-allergens that have a strong association with atopic respiratory disorders such as asthma, rhinitis, eczema, and conjunctivitis.

We thank Jackie Burnham for her help in preparing the manuscript, all the volunteers and the operators who gave up their time so willingly, and the doctors and practice manager at Hythe Medical Centre who made space and time available to us.

Contributors: GTL, JNK, and STH conceived the study, developed the protocol, and obtained funding. JB was the trial manager. JG was responsible for the statistical design and randomisation, and $\mathrm{PP}$ for the analysis. All authors were jointly involved in writing the paper. STH will act as guarantor.
Funding: The study was supported by funding from Vega Grieshaber, the Asthma Allergy and Inflammation Research Trust, and the Foundation for Integrated Medicine.

Competing interests: GTL and JNK formerly had interests in a company involved in the distribution of Vega Grieshaber products and both have received fees for speaking at a seminar on the Vegatest.

1 Kenyon J, ed. Short manual of the Vegatest method. Schiltach, Germany: Vega Grieshaber, 1981.

2 Van Wijk R, Wilegart FAC. Homoeopathic remedies and pressure induced changes and the galvanic resistance of the skin. Utrecht: State University of Utrecht, Research Unit for Complementary Medicine, 1989.

3 Ho MW. The rainbow and the worm-the physics of organisms. Singapore and London: World Scientific, 1993.

4 Tsuei J and Madill P. A food allergy study using the EAV acupuncture technique. Am J Acupunct 1984;12:105-16.

5 Fuller Royal F, Fuller Royal D. Scientific support for electrodiagnosis. $\mathrm{Br}$ Homoeopathic J 1991;18:166-78.

6 Fox A. Determination of neutralisation point for allergic hypersensitivity. Br Homoeopathic J 1987;76:230-4

7 Ali M. Correlation of IgE antibodies with specificity for pollen and mould allergy changes in electrodermal skin responses following exposure to allergens. Am J Clin Pathol 1989;91:357-9.

8 Krop J, Swiesczek J, Wood A. Comparison of ecological testing with the Vegatest method in identifying sensitivities to chemicals, foods and inhalants. Am J Acupunct 1985;13:253-9.

9 Krop J, Lewith, G, Gziut W, Radulescu C. A double-blind, randomised, controlled investigation of electrodermal testing in the diagnosis of allergies. J Altern Complement Med 1997;3:241-8.

10 Dreborg A, Frew A. Allergen standardisation and skin tests. EAACI '93 subcommittee on skin tests. Allergy 1993;14:48-82.

11 Gallant SP, Maibach HI. Reproducibility of allergy epicutaneous techniques. J Allergy Clin Immunol 1973;51:245-50.

12 Basomba A. Evaluation of changes in skin sensitivity by means of skin tests. EAACI'93 subcommittee on skin tests. Allergy 1993;14:71-5.

(Accepted 20 October 2000)

\title{
Treatment for the premenstrual syndrome with agnus castus fruit extract: prospective, randomised, placebo controlled study
}

R Schellenberg for the study group

Institute for Health Care and Science, 35625 Hüttenberg Germany

R Schellenberg senior consultant

Correspondence to: rued.schellenberg. med@t-online.de

BMJ 2001;322:134-7

\section{Abstract}

Objectives To compare the efficacy and tolerability of agnus castus fruit (Vitex agnus castus L extract Ze 440) with placebo for women with the premenstrual syndrome.

Design Randomised, double blind, placebo controlled, parallel group comparison over three menstrual cycles.

Setting General medicine community clinics. Participants 178 women were screened and 170 were evaluated (active 86; placebo 84). Mean age was 36 years, mean cycle length was 28 days, mean duration of menses was 4.5 days.

Interventions Agnus castus (dry extract tablets) one tablet daily or matching placebo, given for three consecutive cycles.

Main outcome measures Main efficacy variable: change from baseline to end point (end of third cycle) in women's self assessment of irritability, mood alteration, anger, headache, breast fullness, and other menstrual symptoms including bloating. Secondary efficacy variables: changes in clinical global impression (severity of condition, global improvement, and risk or benefit) and responder rate (50\% reduction in symptoms).
Results Improvement in the main variable was greater in the active group compared with placebo group $(\mathrm{P}<0.001)$. Analysis of the secondary variables showed significant $(\mathrm{P}<0.001)$ superiority of active treatment in each of the three global impression items. Responder rates were $52 \%$ and $24 \%$ for active and placebo, respectively. Seven women reported mild adverse events (four active; three placebo), none of which caused discontinuation of treatment.

Conclusions Dry extract of agnus castus fruit is an effective and well tolerated treatment for the relief of symptoms of the premenstrual syndrome.

\section{Introduction}

The premenstrual syndrome is a complex combination of psychological symptoms, including irritability, aggression, tension, anxiety, and depression, and somatic changes such as fluid retention, breast tenderness, headache, feeling of bloating, and weight increase. ${ }^{1}$ Women are affected irrespective of socioeconomic status, race, or cultural background, and family clusters are well documented. ${ }^{23}$ The causes of the premenstrual syndrome have not been clearly elucidated ${ }^{4}$ but have been attributed to hormonal change, neurotransmitters, 
prostaglandins, diet, drugs, and lifestyle, so causal treatment is difficult. ${ }^{3}$

The fruits of Vitex agnus castus (the chaste tree) contain a mixture of iridoids and flavonoids, and some compounds similar in structure to the sex hormones have been isolated from the leaves and flowers. ${ }^{5}$ The effects of agnus castus have been described as similar to those of the corpus luteum. ${ }^{67}$ The mechanism of action may also be related to modulation of stress induced prolactin secretion via dopamine, without directly affecting luteinising hormone or follicle stimulating hormone. ${ }^{8-15}$ Binding to opioid receptors, ${ }^{16} \beta$ endorphins, ${ }^{17}$ and neuroactive flavonoids ${ }^{18}{ }^{19}$ may also have a role. The plant has been used traditionally to relieve the symptoms of the premenstrual syndrome, although systematic evaluation of its efficacy is relatively recent. ${ }^{2} 8$ 20-22

We evaluated the effects of agnus castus fruit (Ze $440)$ in a large, prospective, randomised, placebo controlled study over three consecutive menstrual cycles. The study and analysis were planned and conducted under strict methodology.

\section{Methods}

\section{Recruitment and blinding}

All women were outpatients attending six general medicine clinics from April to December 1998. All physicians were experienced in the use the instruments of assessment and underwent training before the study on the scales to enhance consistency within and between centres. In each clinic all assessments were made by the same individual.

Study medication consisted of either active (fruit extract ZE 440: $60 \%$ ethanol $\mathrm{m} / \mathrm{m}$, extract ratio 6-12:1; standardised for casticin; one $20 \mathrm{mg}$ tablet once daily) or placebo (matched for appearance, size, colour, taste, and smell).

The study was performed according to current European Union and International Conference on Harmonisation guidelines on Good Clinical Practice and the Declaration of Helsinki and was approved by the ethics committees of the Hessen and BadenWürttemberg Regional Orders of Physicians.

\section{Selection of participants}

All women were aged $\geqslant 18$ years, had the premenstrual syndrome diagnosed according to the Diagnostic and Statistical Manual of Mental Disorders, third edition, revised (DSM-III-R) ${ }^{23}$ and gave written informed consent before entry. Exclusion criteria were participation in other trials, concomitant psychotherapy, pregnancy or breast feeding, inadequate contraception, dementia, alcohol or drug dependence, concomitant serious medical condition, hypersensitivity to agnus castus, fever, pituitary disease, and concomitant use of sex hormones except oral contraceptives for which the doses were kept unchanged.

Baseline assessment was at the start of the first cycle. Women's self assessment at baseline consisted of the combined scores of the following six symptoms relative to their previous three cycles: irritability, mood alteration, anger, headache, other menstrual symptoms (including bloating), breast fullness. Patients also underwent medical examination, laboratory tests (haematology, biochemistry, pregnancy test), and evalua-

\section{Diagnostic criteria for the premenstrual syndrome}

A: In most menstrual cycles in the past year the symptoms listed under (B) occurred during the last week of the luteal phase and disappeared again a few days after onset of the follicular phase. In menstruating women this phase corresponds to the week before and a few days after the start of menstruation.

B: At least four of the following symptoms must be present in the late luteal phase of most cycles, with at least one symptom being from groups 1, 2, 3, or 4 .

1 Clearly unstable mood (for example, sudden sadness)

2 Clear and persistent irritability or anger

3 Clear anxiety, nervous tension, or feeling of being overwrought

4 Clearly depressive mood, feeling of hopelessness, or reduction in self esteem

5 Reduced interest in activities such as work, family, friends, hobbies

6 Rapid tiring and clear lack of energy

7 Subjective feeling of not being able to concentrate

8 Clear change in eating behaviour, such as increased appetite or craving for sweet foods

9 Sleep disorders such as too much sleep or sleeplessness

10 Other physical symptoms such as tender breasts, feeling of bloating, headache, joint or muscle pain, weight gain

$\mathrm{C}$ : The symptoms are such that they are invariably noticeable and create difficulties in the normal course of daily life.

D: The symptoms are not merely an aggravated expression of the symptoms of other diseases such as depression.

tion of clinical global impression (item 1-severity of condition)..$^{24} \mathrm{~A}$ visit at the start of the second cycle was allowed but not encouraged so as to minimise the chances of closer contacts with the doctor influencing the condition. A visit at the end of the third cycle (end point) was mandatory. Women then underwent full medical examination, laboratory tests (haematology, biochemistry), self assessment, clinical global impression, compliance checks, and adverse events monitoring.

\section{Statistics, assignment, and analysis}

All data were processed and analysed by the department of medical information technology at the University of Giessen. Randomisation was provided centrally in blocks of four. The main efficacy variable prospectively sought in the protocol was change from baseline to end point in the combined scores of the six self assessment items (irritability, mood alteration, anger, headache, other menstrual symptoms including bloating, and breast fullness). Women rated each item using a visual analogue scale ${ }^{25}$ validated for the assessment of the premenstrual syndrome, ranging from 0 (no symptoms) to 10 (unbearable), measured in millimetres on the linear scale. We chose the scale because it was validated and also because it correlates

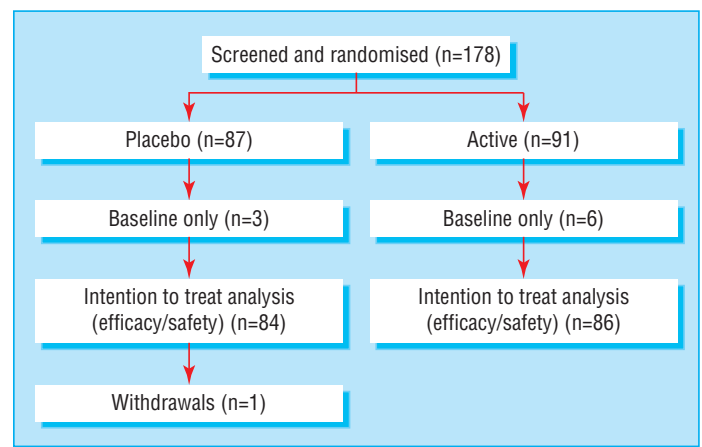

Flow of participants through study 
Table 1 Characteristics of 170 women at entry into study of agnus castus extract as treatment for the premenstrual symdrome (active treatment $n=86$; placebo $n=84$ )

\begin{tabular}{lcc} 
& Mean (SD) & Median \\
\hline Age (years): & $37(8.4)$ & 37 \\
\hline Active & $36(7.4)$ & 37 \\
\hline Placebo & $167(6.2)$ & 168 \\
\hline Height (cm): & $167(5.5)$ & 168 \\
\hline Active & & \\
\hline Placebo & $63(9.8)$ & 61 \\
\hline Weight (kg): & $64(9.8)$ & 63 \\
\hline Active & $28(1.2)$ & 28 \\
\hline Placebo & $28(1.0)$ & 12 \\
\hline Cycle length (days): & 12 \\
\hline Active & $13(1.0)$ & \\
\hline Placebo & $13(1.2)$ & 5.0 \\
\hline Age at menarche (years): & 5.0 \\
\hline Active & $4.6(1.0)$ \\
\hline Placebo & $4.7(0.9)$ \\
\hline Menses duration (days): & $263(104.3)$ \\
\hline Active & $256(112.4)$ \\
\hline Placebo & 240 \\
\hline Patient self assessment on visual analogue score (mm): \\
\hline Active & $5.0(1.0)$ \\
\hline Placebo & \\
\hline Clinical global impression item 1 (severity of condition): \\
\hline Active & \\
\hline Placebo & \\
\hline
\end{tabular}

closely with other more complex tools and is a rapid and straightforward assessment of effect for use in community practice..$^{2125}$ Secondary variables were clinical global impression items 1 (severity of condition), 2 (global improvement or deterioration), and 3 (overall treatment assessment, risk or benefit)

Table 2 Results at end point (end of three consecutive cycles) in 170 women with the premenstrual syndrome (active treatment $n=86$; placebo $n=84$ )

\begin{tabular}{|c|c|c|c|c|}
\hline & \multicolumn{2}{|c|}{ Mean value } & \multirow{2}{*}{$\begin{array}{l}\text { Difference in mean } \\
\text { reduction (active minus } \\
\text { placebo) }(95 \% \mathrm{Cl})\end{array}$} & \multirow[b]{2}{*}{$P$ value ${ }^{*}$} \\
\hline & $\begin{array}{r}\text { Active } \\
(\mathrm{n}=86)\end{array}$ & $\begin{array}{r}\text { Placebo } \\
(\mathrm{n}=84)\end{array}$ & & \\
\hline \multicolumn{5}{|l|}{ Primary efficacy variable: } \\
\hline Differences in self assessment† & -128.5 & -78.1 & $-50.5(-23.5$ to -77.5$)$ & 0.001 \\
\hline \multicolumn{5}{|l|}{ Secondary efficacy variables : } \\
\hline Irritability (self assessment) & -28.9 & -18.2 & $-10.7(-3.4$ to -18.0$)$ & 0.001 \\
\hline Mood alteration (self assessment) & -28.7 & -17.6 & $-11.1(-4.4$ to -17.8$)$ & 0.001 \\
\hline Anger (self assessment) & -22.1 & -11.7 & $-10.3(-3.1$ to -17.5$)$ & 0.001 \\
\hline Headache (self assessment) & -17.8 & -5.9 & $-11.9(-4.3$ to -19.6$)$ & 0.002 \\
\hline Others and bloating (self assessment) & -12.4 & -13.7 & $1.3(-5.5$ to 8.1$)$ & NS \\
\hline Breast fullness (self assessment) & -18.6 & -9.4 & $-9.2(-2.8$ to -15.6$)$ & 0.001 \\
\hline Severity of condition (CGI item 1) & -1.5 & -1.0 & $-0.5(-0.1$ to -0.8$)$ & 0.001 \\
\hline Improvement/deterioration (CGI item 2) & 2.9 & 3.9 & $-1.0(-0.7$ to -1.3$) \ddagger$ & 0.001 \\
\hline Overall assessment risk or benefit (CGI item 3) & 2.9 & 2.2 & $0.7(0.4$ to 1.0$) \ddagger$ & 0.001 \\
\hline Responder rate $(\%) \S$ & 52 & 24 & & \\
\hline $\begin{array}{l}\text { Gl=clinical global impression. } \\
\text { "Mann-Whitney rank sum test. } \\
\text {-Visual analogue scale combined for six items. } \\
\text { Eifference in means with } 95 \% \mathrm{Cl} \text {. }\end{array}$ & & & & \\
\hline
\end{tabular}

Table 3 Adverse events and withdrawals from treatment

\begin{tabular}{lcc} 
& Agnus castus $(\mathbf{n}=\mathbf{8 6})$ & Placebo $(\mathbf{n = 8 4})$ \\
\hline No reporting event & $4(4.7 \%)$ & $3(4.8 \%)$ \\
\hline $\begin{array}{l}\text { All events (regardless of relation to } \\
\text { treatment) }\end{array}$ & $\begin{array}{c}\text { Acne, multiple abscesses, } \\
\text { intermenstrual bleeding, urticaria }\end{array}$ & $\begin{array}{c}\text { Acne, early menstrual period, } \\
\text { gastric upset }\end{array}$ \\
\hline \begin{tabular}{l} 
Withdrawals \\
\hline
\end{tabular} & 0 & 1 (pregnancy) \\
\hline
\end{tabular}

*Each event was reported once, severity was mild for all events. All events resolved without treatment discontinuation. and responder rate, defined as $\geqslant 50 \%$ reduction in self assessed symptoms from baseline.

Our working hypothesis was that active medication is superior to placebo. We defined the intention to treat population as all randomised women who had at least one baseline value and one value after baseline and took any medication. Secondary variables were evaluated descriptively, according to Abt. ${ }^{27}$ We calculated means, SD, medians, 95\% confidence intervals, minima-maxima, and absolute and relative frequencies. We calculated that a difference in mean values of 12 points and 2.5-fold SD would be clinically meaningful. ${ }^{25}$ The expected withdrawal rate was $10 \%$. We calculated that a sample size of 80 per group would give a statistical power of $80 \%{ }^{28}$

\section{Results}

\section{Women's characteristics and flow through study}

A total of 178 women were initially screened and randomised, of whom 170 had at least one baseline and one post-baseline value recorded (intention to treat population, figure). Characteristics at entry were balanced between the two groups (table 1). Twenty three women (13\%) were taking oral contraceptives (11 in the active group).

\section{Efficacy results}

Table 2 shows the results at the end of the treatment period (three cycles). Analysis of the main efficacy variable (difference from baseline to end point between the two groups in self assessed symptoms) rejected the null hypothesis of the two treatments being equal. Patients who received agnus castus had a significant improvement in combined symptoms compared with those on placebo. The self assessment scores were corroborated by the physicians' own evaluation of all three items of the clinical global impression scale. Five of the six self assessment items indicated significant superiority for agnus castus (irritability, mood alteration, anger, headache, and breast fullness), other symptoms including bloating being unaffected by treatment. The responder rate was also favourable for the treated group relative to placebo (52\% v 24\%, respectively). Subgroup analyses that excluded women taking oral contraceptives and included the eight women who were screened but did not have any post-baseline values (assigned mean of combined groups) did not alter the results.

\section{Safety results}

There were few adverse events (table 3). Because of the low incidence of events we could not ascertain the commonest events related to agnus castus, despite the large sample sizes of the two groups. One woman withdrew because of pregnancy (placebo group) 55 days into the trial.

\section{Discussion}

We have shown that agnus castus (Ze 440 extract tablets) is an effective treatment for women with the premenstrual syndrome. Treatment of this condition is a challenge for doctors, who most often treat these women in the community. ${ }^{2}{ }^{20-22}$ Although the condition tends to be mild to moderate, the effects on women can be debilitating. ${ }^{3}$ We planned the study with an open minded approach to the efficacy of agnus cas- 
tus. Although other investigators used active comparators, ${ }^{21}$ we set out to evaluate whether or not this herbal treatment had any relevant effect on the condition. By choosing placebo rather than an active control and by informing patients of the likelihood of receiving placebo we reduced the chances of any psychological influence that an active control would have on the two groups. We reduced the clinic visits to a minimum to allow as little influence as possible from the reassurance that sometimes can be gained from frequent medical check ups. Careful screening of the women resulted in relatively few losses to follow up, which can be a problem in studies of this condition.

We chose the duration of treatment of three cycles to overcome the variability of the symptoms over time, and we set the diagnosis strictly according to established criteria. The instruments of assessment were robust and validated, and all participating physicians underwent prior training with the scales so the results were consistent across the investigating clinics (no centre effect).

Patient acceptance is crucial in the treatment of this condition. The effects of agnus castus were clear to both the women and physicians. We have no data on the progress of symptoms after cessation of treatment, but other researchers have shown that though the effects of treatment gradually decrease over time, they are still felt for as long as three cycles after treatment (Berger et al, personal communication).

Tolerability of agnus castus was good in this study. Although herbal treatments are sometimes misguidedly considered to be completely safe, we did not identify any event related to treatment that could be considered prevalent in this population. In this regard, the fact that patients were aware of the chances of receiving either a herbal or placebo tablet may have played a part in the low incidence of reported events.

\section{Conclusions}

Agnus castus is a well tolerated and effective for the treatment for the premenstrual syndrome, the effects being confirmed by physicians and patients alike. The effects are detected in most main symptoms of the syndrome. This herbal remedy ought to be considered a therapeutic option in women in whom a causal origin for this syndrome cannot be established.

Contributors: E Schrader, Pohlheim, was the study coordinator. The investigators were R Schellenberg (Hüttenberg), G Kunze (Rottweil), E R Pfaff (Mörfelden), A Massing (Offenbach), H Wältner (Albstadt-Tailfingen), Dr M Kirschbaum (UniversitätsFrauenklinik Giessen), R H Boedecker (statistics, Giessen). Dudeck (statistics, Giessen) was responsible for statistics and data management. RS is guarantor.

Funding: Zeller AG, CH-8590, Switzerland supplied the study medication and sponsored the study through the Clinical Research Organisation Praxis Klinische Arzneimittelforschung, Polheim, Germany.

Competing interests: None declared.

1 Chuong CJ, Coulam CB. Current views and the beta-endorphin hypothesis. In: Gies LH, Kase NG, Berkowith C, eds. The premenstrual syndromes. New York: Churchill Livingstone, 1988:75-95.

2 Peters-Welte C, Albrecht M. Regeltempostörungen und PMS. Vitex agnus castus in einer Anwendungsbeobachtung. TW Gynäkologie 1994;7:49-52

3 Küpper C, Loch E-G. Prämenstruelles Syndrom. Deutsche Apotheker Zeitung 1996;136:23-9.

4 Sondheimer S J. Etiology of premenstrual syndrome. In: Smith S, Schiff I eds. Modern management of premenstrual syndrome. New York: Norton Medical Books, 1994:46-54.

5 Brickell C, ed. Royal Horticultural Society encyclopaedia of plants and flowers. London: Dorling Kindersley, 1989.

6 Du Mee C. Vitex agnus castus. Aust J Med Herbalism 1993;5:63-5.

\section{What is already known on this topic}

Women with the premenstrual syndrome are usually seen primary care and are a therapeutic challenge to general practitioners

Treatment of the causes is often impossible, and current treatment of the full range of symptoms is inadequate

\section{What this study adds}

Agnus castus is effective in the treatment of the premenstrual syndrome

The effects were confirmed by women's self assessment and by the doctors' evaluation

Over half the women had a $50 \%$ or greater improvement in their symptoms

Patient acceptance was high and side effects were few and mild

7 Hobbs C. The chaste tree: Vitex agnus castus. Pharm History 1991:23 19-24.

8 Milewicz A, Gejdel E, Sworen H, Sienkiewicz K, Jedrzejak J, Teucher T, et al. Vitex agnus castus-Extrakt zur Behandlung von Regeltempoanomalien infolge latenter Hyperprolaktinämie [Vitex agnus castus extract in the treatment of luteal phase defects due to latent hyperprolactinemia. Results of a randomized placebo-controlled double-blind study]. Drug Res 1993:43:752-6.

9 Sliutz G, Speiser P, Schultz AM, Spona J, Zeillinger R. Agnus castus extracts inhibit prolactin secretion of rat pituitary cells. Hormone Metab Res 1993;25:253-5

10 Winterhoff H, Gorkow C, Behr B. Die Hemmung der Laktation bei Ratten als indirekter Beweis für die Senkung von Prolaktin durch Agnus castus. Z Phytotherapie 1991;12:175-9.

11 Wuttke W, Gorkow S, Jarry H. Dopaminergic compounds in Vitex agnu castus. In: Loew D, Rietbrock N, eds. Phytopharmaka in Forschung und klinischer Anwendung, Darmstadt: Steinkopff, Verlag, 1995:81-9.

12 Jarry H, Leonhardt S, Gorkow C, Wuttke W. In vitro prolactin but not LH and FSH release is inhibited by compounds in extracts of Agnus castus: direct evidence for a dopaminergic principle by the dopamine receptor assay. Exp Clin Endocrinol 1994;102:448-54.

13 Merz PG, Gorkow C, Schrödter A, Rietbrock S, Sieder C, Loew D, et al. The effects of a special Agnus castus extract (BP 1095E1) on prolactin secretion in healthy male subjects. Exp Clin Endocrinol Diabetes secretion in heall $104: 447-53$.

14 Berger D, Burkard W, Schaffner W, Meier B. Rezeptorbindungsstudien mit daraus isolierten Substanzen. In: Meier B, Hoberg E, eds. Agni-castifructus-Neue Erkenntnisse zur Qualität und Wirksamkeit; Z Phytotherapie 1999;20:140-58.

15 Carroll BJ, Steiner M. The psychobiology of premenstrual dysphoria: the role of prolactin. Psychoneuroendocrinol 1978;3:171-80.

16 Brugisser R, Burkard W, Simmen U, Schaffner W. Untersuchungen an Opioid-Rezeptoren mit Vitex agnus-castus L. In: Meier B, Hoberg E, eds. Agni-casti-fructus-Neue Erkenntnisse zur Qualität und Wirksamkeit. Z Phytotherapie 1999;20:140-58

17 Samochowiec L, Glaesmer R, Samochowiec J. Einfluss von Möchspfeffer auf die Konzentration von beta-Endorphin im Serum weiblicher Ratten. Ärztezeitschr Naturheilverfahren 1998;39:213-5.

18 Medina JH, Viola H, Wolfman C, Marder M, Wasowski C, Calvo D, et al. Neuroactive flavonoids: new ligands for the benzodiazepine receptors. Phytomedicine 1998;5:235-43.

19 Shiah IS, Yatham LN. GABA function in mood disorders: an update and critical review. Life Sciences 1998;63:1289-303.

20 Jarry H, Leonhardt S, Wuttke W, Behr B, Gorkow C. Agnus castus als dopaminerges Wirkungsprinzip in Mastodynon N. Z Phytotherapie 1991;12:77-82.

21 Lauritzen C, Reuter HD, Repges R, Böhnert KJ, Schmidt U. Treatment of premenstrual tension syndrome with Vitex agnus castus-controlled, double-blind study versus pyridoxine. Phytomedicine 1997;4:183-9.

22 Roeder D. Therapie von Zyklusstörungen mit Vitex agnus-castus. Z Phytotherapie 1994;15:155-9.

23 American Psychiatric Association. Diagnostic and statistical manual of mental disorders. 3rd ed, rev. Washington, DC: American Psychiatric Association, 1987.

24 National Institute of Mental Health. 028 CGI clinical global impressions. In: Guy W, ed. ECDEU assessment for psychopharmacology. Rev ed. Rockville Maryland, 1976:217-22

25 Casper RF, Powell AM. Premenstrual syndrome: documentation by a linear analog scale compared with two descriptive scales. Am J Obstet Gynecol 1986;155:862-7.

26 Steiner M, Haskett RF, Carroll BJ. Premenstrual tension syndrome: the development of research diagnostic criteria and new rating scales. Acta Psychiatr Scand 1980;62:177-90.

27 Abt K. Descriptive data analysis: a concept between confirmatory and exploratory data analysis. Meth Inform 1987;26:77-88.

28 Machin D, Campbell MJ. Statistical tables for the design of clinical trials. Oxford: Blackwell Scientific Publications, 1987:81-3.

(Accepted 17 November 2000) 